JurnaI lmu Ilmu Agribisnis: Journal of Agribusiness Science, 9(3), Agustus 2021

\title{
ANALISIS FINANSIAL DAN STRATEGI PENGEMBANGAN BUDIDAYA JAMUR MERANG DI RAJABASA JAYA BANDAR LAMPUNG
}

\author{
(Financial Analysis and Development Strategy of Straw Mushroom Farming in Rajabasa Jaya \\ Bandar Lampung City)
}

Fiko Alif Putra, Teguh Endaryanto, Serly Silviyanti

\begin{abstract}
Jurusan Agribisnis, Fakultas Pertanian, Universitas Lampung, Jl. Prof. Dr. Soemantri Brojonegoro No.1
Bandar Lampung, e-mail: teguh.endaryanto@fp.unila.ac.id
\end{abstract}

\begin{abstract}
This study aims to analyze the financial viability and development strategy of straw mushroom farming in Rajabasa Jaya. This research was carried out in September 2018 in Rajabasa Jaya, Rajabasa District, Bandar Lampung City that was intentionally chosen by consideration of the straw mushroom farming being the example for the straw mushroom farming in Bandar Lampung City. Respondent in this research was the farmer in Rajabasa Jaya. The first objective was quantitative analyzed by financial analysis (Gross Benefit Cost Ratio (Gross B/C), Net B/C, Net Present Value (NPV), Internal Rate Return (IRR) dan Payback Period $(P P))$ with interest rate of $7 \%$ and economic life of business by 6 years. The second objective was descriptive analyzed by SWOT analysis. Based on the result, the straw mushroom farming is financially feasible because of the Gross B/C and Net B/C values of more than 1, NPV value more than 0, IRR value higher than interest rate, and PP value shorter than economic life of business. The strategy needed to develop the straw mushroom farming are to increase the production of quality mushroom, improve customer relationships, start the promotion of mushroom businesses to expand market network, and records the finance of straw mushroom farm.
\end{abstract}

Key words: development strategy, financial analysis, straw mushroom

\section{PENDAHULUAN}

Pasar jamur internasional masih terbuka lebar, Kegiatan ekspor komoditas jamur setiap bulan cenderung mengalami peningkatan yang signifikan. Beberapa negara yang menjadi konsumen jamur terbesar rata-rata memiliki tingkat konsumsi yang tinggi seperti Kanada dan Eropa dengan konsumsi $>1,5 \mathrm{~kg} / \mathrm{kapita} /$ tahun, Inggris \pm 1 $\mathrm{kg} / \mathrm{kapita} / \mathrm{tahun}$ dan Amerika Serikat $\pm 0,5$ $\mathrm{kg} / \mathrm{kapita} / \mathrm{tahun}$ Indonesia hanya mampu memasok $\pm 0,9$ persen dari permintaan ekspor jamur. Kondisi ini sangat disayangkan, karena prospek pasar jamur yang semakin tinggi ternyata belum dapat dimanfaatkan dengan optimal oleh negara kita (Kurniawan 2011).

Konsumsi jamur masyarakat Indonesia pada tahun 2010 sebesar $0,0417 \mathrm{~kg}$, meningkat menjadi $0,0574 \mathrm{~kg}$ pada tahun 2011. Pada tahun 2012 dan 2013 konsumsi tetap sama dengan tahun 2011, kemudian pada tahun 2014 konsumsi masyarakat Indonesia meningkat kembali menjadi $0,0886 \mathrm{~kg}$ (Kementerian Pertanian 2017). Hal ini menunjukkan bahwa walaupun konsumsi jamur masyarakat Indonesia tidak setinggi konsumsi jamur masyarakat Eropa, namun konsumsi jamur di Indonesia terus mengalami peningkatan tiap tahunnya. Konsumsi masyarakat Indonesia yang terus meningkat tentu akan semakin meningkatkan peluang usaha jamur.

Permintaan jamur yang tinggi telah membuat jamur punya persaingan harga yang cukup signifikan. Tahun 2017 harga jamur merang per $\mathrm{kg}$ berkisar antara Rp25.000 s/d Rp40.000/kg di pasar sayur atau pasar tradisional. Sementara untuk harga jamur merang di supermarket dijual dengan harga Rp40.000 s/d Rp100.000/kg. Harga jamur merang kering sekitar Rp35.000 s/d Rp45.000/kg (Novarinka 2017).

Produksi jamur di Provinsi Lampung mengalami peningkatan dari tahun 2011-2014. Kota Bandar Lampung berkontribusi besar dalam produksi jamur di Provinsi Lampung (Dinas Pertanian Tanaman Pangan dan Hortikultura Provinsi Lampung 2017). Salah satu budidaya jamur merang yang ada di Kota Bandar Lampung berada di Kelurahan Rajabasa Jaya, Kecamatan Rajabasa. Petani yang membudidayakan jamur di Kelurahan Rajabasa Jaya adalah Bapak Maman yang memulai budidaya jamur merang pada tahun 2013. Budidaya jamur merang ini masih bertahan sampai 
sekarang, namun mengalami penurunan produksi. Pengalaman dan wawasan petani menjadi penyebab menurunnya produksi budidaya jamur merang. Berdasarkan masalah tersebut, penelitian ini bertujuan untuk menganalisis kelayakan finansial budidaya jamur merang dan menyusun strategi pengembangan budidaya jamur merang di Rajabasa Jaya, Kota Bandar Lampung.

\section{METODE PENELITIAN}

Penelitian ini dilakukan di Kelurahan Rajabasa Jaya, Kecamatan Rajabasa, Kota Bandar Lampung. Lokasi penelitian ditentukan secara sengaja (purposive) dengan pertimbangan bahwa bahwa budidaya ini menjadi contoh untuk para pengembang budidaya jamur merang yang ada di Kota Bandar Lampung. Metode penelitian yang digunakan pada penelitian ini adalah studi kasus. Responden pada penelitian ini adalah pemilik budidaya jamur merang yaitu Bapak Maman.

Data dalam penelitian terdiri dari data primer dan sekunder. Data primer diperoleh melalui wawancara langsung. Wawancara menggunakan daftar pertanyaan (kuesioner) yang telah dipersiapkan terlebih dahulu. Data sekunder diperoleh dari studi literatur, laporan-laporan, publikasi artikel dan pustaka lainnya yang berhubungan dengan penelitian ini serta lembaga atau instansi terkait.

Tujuan pertama penelitian ini dianalisis menggunakan analisis finansial dengan umur ekonomis yang digunakan untuk analisis adalah 6 tahun berdasarkan usia ekonomis dari kumbung. Tingkat suku bunga yang digunakan sebesar 7 persen berdasarkan tingkat suku bunga Kredit Usaha Rakyat (KUR) ritel Bank Rakyat Indonesia (BRI) tahun 2018 yang dihitung dengan Compound Factor. Penggunaan penghitungan dengan Compound Factor adalah untuk mengubah nilai yang diperoleh budidaya jamur merang pada masa lalu menjadi nilai pada saat sekarang. Alat yang digunakan untuk menganalisis finansial usaha adalah Gross Benefit Cost Ratio (Gross B/C), Net Benefit Cost Ratio (Net B/C Ratio), Net Present Value (NPV), Internal Rate of Return (IRR), Payback Period (PP). Analisis yang digunakan untuk menjawab tujuan ke dua menggunakan analisis SWOT.

\section{Analisis Finansial}

a. Net Present Value (NPV)
NPV adalah selisih antara penerimaan dan biaya budidaya jamur merang yang nilainya sudah disesuaikan dengan Compound Factor pada penelitian ini. Nilai NPV yang lebih besar dari nol $(>0)$ menunjukkan bahwa usaha layak untuk diteruskan. Sebaliknya, Nilai NPV yang lebih kecil dari nol $(<0)$ menunjukkan bahwa usaha tidak layak untuk diteruskan.

$$
\mathrm{NPV}=\left\{\frac{N C F_{1}}{(1+i)^{1}}+\frac{N C F_{2}}{(1+i)^{2}}+\ldots+\frac{N C F_{n}+T F C}{(1+i)^{n}}\right\}-I I / I O
$$

Keterangan :

$\mathrm{NCF}=$ Net Cash Flow

$\mathrm{TCF}=$ Terminal Cash Flow

$\mathrm{n} \quad=$ Umur investasi

i = Discount Factor

$\mathrm{II} / \mathrm{IO}=$ Initial Investment/Incremental Outlay

$\mathrm{NPV}=$ Net Present Value

\section{b. Net Benefit Cost Ratio (Net B/C)}

Net $\mathrm{B} / \mathrm{C}$ adalah perbandingan antara NPV yang bernilai positif dengan NPV yang bernilai negative pada budidaya jamur merang. Nilai Net B/C yang lebih besar dari satu (>1) menunjukkan bahwa usaha jamur merang Kelompok Tani Jamur Berkah Jaya layak untuk diteruskan.

$$
\text { Net } \frac{B}{C} \text { Ratio }=\frac{\sum P V \text { net } B \text { positif }}{\sum P V n e t B \text { negatif }}=\frac{n e t \bar{B}}{n e t \bar{C}}
$$

Keterangan :

$\mathrm{PV}=$ Present Value

\section{c. Gross Benefit Cost Ratio (Gross B/C)}

Gross B/C adalah perbandingan antara presen value penerimaan dengan present value biaya pada budidaya jamur merang. Nilai Gross B/C yang lebih besar dari satu (>1) menunjukkan bahwa usaha jamur merang Kelompok Tani Jamur Berkah Jaya layak untuk diteruskan.

$$
\text { Gross } B / C \text { Ratio }=\frac{\sum P V \text { gross benefit }}{\sum P V \text { gross } \cos t}
$$

Keterangan :

$\mathrm{PV}=$ Present Value

\section{d. Internal Rate Return (IRR)}

IRR adalah digunakan sebagai indicator efesiensi biaya budidaya jamur merang. Nilai IRR yang 
lebih besar dari tingkat suku bunga menunjukkan bahwa usaha layak untuk diteruskan.

$$
N P V=N o l=\left\{\frac{N C F_{1}}{(1+I R R)^{1}}+\frac{N C F_{2}}{(1+I R R)^{2}}+\ldots+\frac{N C F_{n}+T F C}{(1+I R R)^{n}}\right\}-I I / I O
$$

Keterangan :

$$
\begin{array}{ll}
\mathrm{NCF} & =\text { Net Cash Flow } \\
\mathrm{TCF} & =\text { Terminal Cash Flow } \\
\mathrm{n} & =\text { Umur investasi } \\
\mathrm{IRR} & =\text { Intenal Rate of Return } \\
\mathrm{II} / \mathrm{IO} & =\text { Initial Investment/Incremental Outlay } \\
\mathrm{NPV} & =\text { Net Present Value }
\end{array}
$$

\section{e. Payback Period (PP)}

PP digunakan untuk mengetahui jangka waktu yang diperlukan untuk mengembalikan modal investasi budidaya jamur merang. Nilai PP yang lebih pendek dari umur ekonomis usaha menunjukkan bahwa usaha layak untuk diteruskan.

$$
P p=\frac{I_{0}}{A_{n}} \times 1 \text { Tahun }=\ldots
$$

Keterangan :

$$
\begin{aligned}
\mathrm{Pp} & =\text { Payback Period } \\
\mathrm{I}_{0} & =\text { Investasi Awal } \\
\mathrm{A}_{\mathrm{n}} & =\text { Manfaat (Benefit) yang diperoleh tiap } \\
& \text { periode }
\end{aligned}
$$

\section{f. Analisis Sensitivitas}

Analisis sensitivitas digunakan untuk melihat apa yang terjadi jika terjadi perubahan pada budidaya jamur merang.

$$
\mathrm{SA}=\left(P-P^{*}\right)+\frac{N P V^{+}}{N P V^{+}-N P V^{-}} \times 100 \%=\ldots \%
$$

Keterangan :

SA = Tingkat kepekaan terhadap perubahan

$\mathrm{P}^{*} \quad=$ Perubahan yang terjadi pada harga

$\mathrm{NPV}^{+}=$Adalah nilai NPV positif yang telah dihitung sebelum ada perubahan

$\mathrm{NPV}^{-}=$Adalah nilai NPV negatif yang setelah ada perubahan

Kriteria kepekaan :

(1.) Jika laju kepekaan lebih dari satu, maka usaha sensitif terhadap perubahan
(2.) Jika laju kepekaan kurang dari satu, maka usaha tidak sensitif terhadap perubahan

\section{Strategi Pengembangan}

Strategi pengembangan usaha ini menggunakan metode analisis SWOT. Penyusunan strategi pengembangan dalam penelitian ini melalui beberapa tahap yaitu: Pertama, menentukan lima faktor lingkungan internal dan eksternal yang paling penting kedalam faktor strategi masing masing. Kedua, pemberian bobot serta perangkingan komponen faktor strategi internal dan komponen faktor strategi eksternal menggunakan matriks Internal Factors Analysis Summary (IFAS) dan External Factors Analysis Summary (EFAS) dengan skala 0,0 (tidak penting) sampai 1,0 (paling penting). Ketiga, menyilangkan lima komponen dari hasil perangkingan matriks IFAS dan EFAS untuk menghasilkan 100 alternatif strategi. Keempat, dilakukan pembobotan terhadap 100 alternatif strategi berdasarkan visi misi yang dimiliki budidaya jamur merang, sehingga diperoleh sepuluh strategi prioritas.

\section{HASIL DAN PEMBAHASAN}

\section{Gambaran Umum Budidaya Jamur Merang}

Budidaya jamur merang ini berada di Kelurahan Rajabasa Jaya, Kecamatan Rajabasa, Kota Bandar lampung. Budidaya jamur merang ini mulai berjalan sejak tahun 2013. Proses budidaya jamur merang berlangsung sekitar 28 hari. Waktu pengomposan media tanam berlangsung selama 8 hari. Waktu sterilisasi berlangsung selama 1 hari. Penanaman bibit dan perawatan jamur merang berlangsung selama 13-15 hari dan pemanenan jamur merang berlangsung selama 5 hari. Untuk setiap musim tanam, media tanam yang sudah digunakan harus diganti dengan media tanam yang baru.

\section{Biaya Investasi Budidaya Jamur Merang}

Biaya investasi budidaya jamur merang adalah biaya yang dikeluarkan sebelum memulai budidaya jamur merang dan memiliki umur ekonomis. Investasi yang digunakan untuk budidaya jamur merang terdiri dari 2 unit drum, 1 unit blower, 1 unit selang sepanjang $20 \mathrm{~m}, 2$ unit ganco, 5 unit baskom, 2 unit ember, 2 unit pisau cutter, 1 unit troli, 1 unit bak semen, 1 unit termometer, 1 unit sprayer, 1 unit terpal dan 2 unit kumbung berukuran $6 \times 4 \mathrm{~m}^{2}$. 
Tabel 1. Total Biaya Budidaya Jamur Merang

\begin{tabular}{crrr}
\hline Thn & \multicolumn{1}{c}{$\begin{array}{c}\text { Investasi } \\
(\mathrm{Rp})\end{array}$} & $\begin{array}{l}\text { Operasional } \\
(\mathrm{Rp})\end{array}$ & $\begin{array}{l}\text { Total biaya } \\
(\mathrm{Rp})\end{array}$ \\
\hline 1 & $12.425 .000,00$ & $7.527 .141,51$ & $19.952 .141,51$ \\
2 & $180.000,00$ & $9.677 .753,37$ & $9.857 .753,37$ \\
3 & $180.000,00$ & $9.677 .753,37$ & $9.857 .753,37$ \\
4 & $445.000,00$ & $9.677 .753,37$ & $10.122 .753,37$ \\
5 & $180.000,00$ & $7.527 .141,51$ & $7.707 .141,51$ \\
6 & $180.000,00$ & $8.602 .447,44$ & $8.782 .447,44$ \\
\hline Total & $13.590 .000,00$ & $52.689 .990,55$ & $66.279 .990,55$ \\
\hline
\end{tabular}

Penelitian ini tidak sejalan dengan penelitian terdahulu yang dilakukan Chandra, Lestari dan Situmorang (2014) tentang analisis usahatani dan pemasaran jamur tiram dengan cara konvensional dan jaringan (Multi Level Marketing) di Provinsi Lampung. Pada penelitian terdahulu diketahui bahwa petani menggunakan luas lahan untuk budidaya jamur tiram minimal $201 \mathrm{~m}^{2}-300 \mathrm{~m}^{2}$, sedangkan pada penelitian ini diketahui bahwa luas lahan yang dibutuhkan untuk budidaya jamur merang leboh kecil yaitu sebesar $24 \mathrm{~m}^{2}$.

Investasi budidaya jamur merang ini memiliki umur ekonomis yang berbeda-beda. Umur ekonomis investasi terdiri dari 1 tahun, 3 tahun dan 6 tahun. Investasi yang memiliki umur ekonomis 1 tahun adalah drum. Investasi yang memiliki umur ekonomis 3 tahun adalah baskom, ember, pisau cutter dan terpal. Investasi yang memiliki umur ekonomis 6 tahun adalah kumbung, blower, selang, ganco, troli, bak semen, termometer dan sprayer. Biaya investasi yang dikeluarkan selama 6 tahun dapat dilihat pada Tabel 1. Berdasarkan Tabel 1 diketahui bahwa total biaya investasi yang dikeluarkan selama 6 tahun sebesar Rp13.590.000,00.

\section{Biaya Operasional Budidaya Jamur Merang}

Biaya operasional budidaya jamur merang adalah biaya yang dikeluarkan tiap satu musim tanam. Biaya operasional yang dikeluarkan selama 6 tahun dapat dilihat pada Tabel 1. Berdasarkan Tabel 1 diketahui bahwa biaya operasional yang dikeluarkan selama 6 tahun sebesar Rp52.689.990,55. Biaya operasional yang dikeluarkan terdiri dari biaya tunai dan biaya diperhitungkan. Biaya tunai yang dikeluarkan terdiri dari tandan kosong kelapa sawit sebanyak 0,5 rit, bibit jamur merang sebanyak $50 \mathrm{log}$, dedak sebanyak $30 \mathrm{~kg}$, kapur sirih sebanyak $6 \mathrm{~kg}$, listrik dan air. Biaya diperhitungkan yang dikeluarkan adalah Tenaga Kerja Dalam Keluarga (TKDK).

\section{Penerimaan Budidaya Jamur Merang}

Penerimaan budidaya jamur merang adalah hasil kali antara jumlah produksi dengan harga jual persatuan jamur merang. Penerimaan yang didapatkan selama 6 tahun dapat dilihat pada Tabel 2. Berdasarkan Tabel 2 diketahui bahwa produksi budidaya jamur merang selama 6 tahun sebesar $4.689,50 \mathrm{~kg}$. Penerimaan yang diperoleh selama 6 tahun adalah sebesar Rp117.237.500,00. Penelitian ini tidak sejalan dengan penelitian terdahulu yang dilakukan Munawar dan Kartika (2017) tentang produksi dan kualitas jamur merang (Volvariella Volvaceae) pada Kelompok Tani "Mitra Usaha" Kabupaten Karawang. Pada penelitian terdahulu diketahui bahwa budidaya jamur merang yang menggunakan jerami sebagai media tanam dapat menghasilkan produksi mencapai $200 \mathrm{~kg}$ per musim tanam, sedangkan pada penelitian ini diketahui bahwa budidaya jamur merang menggunakan media tanam tandan kosong kelapa sawit sebagai media tanam dengan rata-rata produksi sebesar $95,74 \mathrm{~kg}$ per musim tanam.

\section{Analisis Finansial Budidaya Jamur Merang}

Analisis finansial budidaya jamur merang digunakan untuk menganalisis kelayakan dari budidaya jamur merang. Penelitian sejenis yang dijadikan pembanding dengan penelitian ini adalah Devy, Hasyim dan Situmorang (2018) tentang Analisis kelayakan finansial dan risiko usaha budidaya jamur tiram di Provinsi Lampung. Pada penelitian pembanding diketahui umur ekonomis kumbung pada budidaya jamur tiram selama 10 tahun. Pada penelitian ini diketahui umur ekonomis kumbung pada budidaya jamur merang selama 6 tahun. Hal ini menunjukkan bahwa kumbung yang digunakan pada budidaya jamur merang memiliki umur ekonomis yang lebih singkat dibandingkan dengan kumbung yang digunakan untuk budidaya jamur tiram. Kriteria kelayakan budidaya jamur merang dapat dilihat pada Tabel 3 .

Tabel 2. Penerimaan Budidaya Jamur Merang

\begin{tabular}{cccc}
\hline Thn & $\begin{array}{c}\text { Produksi } \\
(\mathrm{Kg})\end{array}$ & $\begin{array}{c}\text { Harga } \\
(\mathrm{Rp})\end{array}$ & $\begin{array}{c}\text { Penerimaan } \\
(\mathrm{Rp})\end{array}$ \\
\hline 1 & 665,00 & $25.000,00$ & $16.625 .000,00$ \\
2 & 855,00 & $25.000,00$ & $21.375 .000,00$ \\
3 & 855,00 & $25.000,00$ & $21.375 .000,00$ \\
4 & 810,00 & $25.000,00$ & $20.250 .000,00$ \\
5 & 635,70 & $25.000,00$ & $15.892 .500,00$ \\
6 & 868,80 & $25.000,00$ & $21.720 .000,00$ \\
\hline Total & $4.689,50$ & & $117.237 .500,00$ \\
\hline
\end{tabular}


Tabel 3. Kriteria Kelayakan Budidaya Jamur Merang

\begin{tabular}{llr}
\hline Kriteria & Nilai & Keterangan \\
\hline NPV & Rp55.948.721,21 & Layak \\
Net B/C & 12,23 & Layak \\
Gross B/C & 1,67 & Layak \\
IRR & $313,16 \%$ & Layak \\
PP & 2,42 & Layak \\
\hline
\end{tabular}

Berdasarkan Tabel 3 diketahui bahwa budidaya jamur merang layak untuk dijalankan karena nilai NPV lebih dari besar dari 0 . Nilai Net $\mathrm{B} / \mathrm{C}$ sebesar 12,23 yang berarti setiap Rp1,00 biaya bersih yang dikeluarkan dapat menghasilkan penerimaan bersih sebesar Rp12,23. Nilai Gross B/C sebesar 1,67 yang berarti setiap Rp1,00 biaya yang dikeluarkan dapat menghasilkan penerimaan sebesar Rp1,67. Nilai IRR sebesar 313,16 persen yang berarti nilai IRR lebih besar dari tingkat suku bunga (7 persen). Nilai PP yang diperlukan untuk mengembalikan nilai investasi usaha adalah 2 tahun 5 bulan 1 hari yang berarti nilai PP lebih cepat dibandingkan umur ekonomis usaha. Penelitian ini sejalan dengan penelitian terdahulu yang dilakukan Wiratma, Wibowo dan Purnomo (2015) tentang -

Tabel 4. Kerangka Matriks Faktor Internal Budidaya Jamur Merang

\begin{tabular}{|c|c|c|c|c|}
\hline Komponen & Bobot & Rating & Skor & Rank \\
\hline Kekuatan & & & & \\
\hline $\begin{array}{l}\text { Produk yang } \\
\text { dihasikan } \\
\text { berkualitas }\end{array}$ & 0,12 & 4 & 0,49 & 1 \\
\hline $\begin{array}{l}\text { Lokasi mudah } \\
\text { dijangkau semua } \\
\text { kendaraan }\end{array}$ & 0,09 & 3 & 0,27 & 5 \\
\hline $\begin{array}{l}\text { Pengelola usaha } \\
\text { adalah pemilik } \\
\text { usaha }\end{array}$ & 0,10 & 3 & 0,30 & 4 \\
\hline $\begin{array}{l}\text { Penggunaan } \\
\text { tenaga kerja } \\
\text { sedikit }\end{array}$ & 0,10 & 3 & 0,30 & 3 \\
\hline $\begin{array}{l}\text { Sudah memiliki } \\
\text { pelanggan tetap }\end{array}$ & 0,10 & 4 & 0,40 & 2 \\
\hline Total & 0,51 & & 1,76 & \\
\hline Kelemahan & & & & \\
\hline $\begin{array}{l}\text { Volume produksi } \\
\text { yang tidak stabil }\end{array}$ & 0,10 & 4 & 0,40 & 1 \\
\hline $\begin{array}{l}\text { Tidak ada } \\
\text { petunjuk jalan } \\
\text { menuju lokasi }\end{array}$ & 0,10 & 3 & 0,30 & 4 \\
\hline $\begin{array}{l}\text { Pembukuan yang } \\
\text { belum baik }\end{array}$ & 0,04 & 2 & 0,09 & 5 \\
\hline $\begin{array}{l}\text { Belum } \\
\text { menggunakan } \\
\text { TKLK }\end{array}$ & 0,11 & 3 & 0,33 & 3 \\
\hline $\begin{array}{l}\text { Kurangnya } \\
\text { promosi }\end{array}$ & 0,13 & 3 & 0,40 & 2 \\
\hline Total & 0,49 & & 1,52 & \\
\hline
\end{tabular}

Tabel 4. Kerangka Matriks Faktor Internal Budidaya Jamur Merang

\begin{tabular}{lcccc}
\hline Komponen & Bobot & Rating & Skor & Rank \\
\hline $\begin{array}{l}\text { Kekuatan } \\
\text { Produk yang } \\
\text { dihasikan } \\
\text { berkualitas }\end{array}$ & 0,12 & 4 & 0,49 & 1 \\
$\begin{array}{l}\text { Lokasi mudah } \\
\text { dijangkau semua } \\
\text { kendaraan }\end{array}$ & 0,09 & 3 & 0,27 & 5 \\
$\begin{array}{l}\text { Pengelola usaha } \\
\text { adalah pemilik }\end{array}$ & 0,10 & 3 & 0,30 & 4 \\
$\begin{array}{l}\text { usaha } \\
\text { Penggunaan }\end{array}$ & 0,10 & 3 & 0,30 & 3 \\
$\begin{array}{l}\text { tenaga kerja } \\
\text { sedikit }\end{array}$ & 0,10 & 4 & 0,40 & 2 \\
$\begin{array}{l}\text { Sudah memiliki } \\
\text { pelanggan tetap }\end{array}$ & 0,51 & & 1,76 & \\
\hline Total & 0,10 & 4 & 0,40 & 1 \\
\hline $\begin{array}{l}\text { Kelemahan } \\
\text { Volume produksi }\end{array}$ & 0,10 & 3 & 0,30 & 4 \\
$\begin{array}{l}\text { yang tidak stabil } \\
\text { Tidak ada } \\
\text { petunjuk jalan } \\
\text { menuju lokasi }\end{array}$ & 0,04 & 2 & 0,09 & 5 \\
$\begin{array}{l}\text { Pembukuan yang } \\
\text { belum baik } \\
\text { Belum } \\
\text { menggunakan } \\
\text { TKLK }\end{array}$ & 0,11 & 3 & 0,33 & 3 \\
$\begin{array}{l}\text { Kurangnya } \\
\text { promosi }\end{array}$ & 0,13 & 3 & 0,40 & 2 \\
\hline Total & 0,49 & & 1,52 & \\
\hline
\end{tabular}

Studi analisis kelayakan finansial pembudidayaan jamur merang (Volvariella Volvaceae). Persamaan penelitian ini dengan penelitian terdahulu adalah masa payback period yang kurang dari 3 tahun.

\section{Strategi Pengembangan Budidaya Jamur Merang}

Stategi pengembangan budidaya jamur merang dilakukan untuk menentukan strategi yang tepat untuk budidaya jamur merang. Faktor internal terdiri dari kekuatan dan kelemahan dan faktor eksternal terdiri dari peluang dan ancaman. Faktor internal dan eksternal mempengaruhi perkembangan budidaya jamur merang. Komponen faktor internal dan eksternal yang digunakan dapat dilihat pada Tabel 4 dan Tabel 5. Berdasarkan tabel 4, diketahui bahwa bobot kerangka matriks faktor internal budidaya jamur merang sebesar 0,49 dan skor kerangka matriks faktor internal budidaya jamur merang sebesar 1,52. Berdasarkan tabel 5, diketahui bahwa bobot kerangka matriks faktor eksternal budidaya jamur merang sebesar 0,53 dan skor kerangka matriks faktor internal budidaya jamur merang sebesar 3,23 . 
Tabel 5. Kerangka Matriks Faktor Eksternal Budidaya Jamur Merang

\begin{tabular}{|c|c|c|c|c|}
\hline Komponen & Bobot & Rating & Skor & Rank \\
\hline \multicolumn{5}{|l|}{ Peluang } \\
\hline $\begin{array}{l}\text { Bantuan fisik dan } \\
\text { non fisik } \\
\text { pemerintah }\end{array}$ & 0,07 & 2 & 0,13 & 5 \\
\hline $\begin{array}{l}\text { Pesaing sejenis } \\
\text { masih sedikit }\end{array}$ & 0,10 & 4 & 0,40 & 2 \\
\hline $\begin{array}{l}\text { Penerapan } \\
\text { teknologi dalam } \\
\text { usaha jamur } \\
\text { merang }\end{array}$ & 0,10 & 3 & 0,30 & 4 \\
\hline $\begin{array}{l}\text { Iklim dan cuaca } \\
\text { tidak } \\
\text { mempengaruhi } \\
\text { budidaya jamur } \\
\text { merang }\end{array}$ & 0,09 & 4 & 0,36 & 3 \\
\hline $\begin{array}{l}\text { Kebutuhan jamur } \\
\text { merang tinggi }\end{array}$ & 0,11 & 4 & 0,44 & 1 \\
\hline Total & $\mathbf{0 , 4 7}$ & & 1,63 & \\
\hline \multicolumn{5}{|l|}{ Ancaman } \\
\hline $\begin{array}{l}\text { Kurangnya } \\
\text { bantuan fisik dari } \\
\text { pemerintah }\end{array}$ & 0,10 & 2 & 0,20 & 5 \\
\hline $\begin{array}{l}\text { Kemunculan } \\
\text { pesaing sejenis }\end{array}$ & 0,10 & 3 & 0,30 & 4 \\
\hline $\begin{array}{l}\text { Kesulitan } \\
\text { mengikuti } \\
\text { perkembangan } \\
\text { teknologi }\end{array}$ & 0,11 & 3 & 0,33 & 3 \\
\hline $\begin{array}{l}\text { Iklim dan cuaca } \\
\text { yang tidak } \\
\text { menentu }\end{array}$ & 0,10 & 4 & 0,40 & 1 \\
\hline $\begin{array}{l}\text { Perekonomian } \\
\text { yang tidak stabil }\end{array}$ & 0,12 & 3 & 0,37 & 2 \\
\hline Total & $\mathbf{0 , 5 3}$ & & 3,23 & \\
\hline
\end{tabular}

Berdasarkan total skor dari Tabel 4 dan Tabel 5, maka selanjutnya adalah membuat diagram SWOT dengan menggunakan selisih total skor kekuatan dan kelemahan dari faktor internal dengan selisih total skor peluang dan ancaman dari faktor eksternal. Selisih total skor kekuatan dan kelemahan dari faktor internal sebesar $+0,23$ untuk mengisi titik potong sumbu X (W-S). Selisih total skor peluang dan ancaman dari faktor eksternal sebesar $+0,03$ untuk mengisi titik potong sumbu $\mathrm{Y}$ (O-T).

Gambar 1 menunjukkan bahwa budidaya jamur merang berada pada kuadran I (Growth), rekomendasi strategi yang diberikan adalah Growth Oriented Strategy yang artinya mendukung kebijakan pertumbuhan agresif. Organisasi disarankan mengarahkan seluruh potensi internal usaha untuk memanfaatkan peluang yang ada (Rangkuti, 2006). Penelitian ini tidak sejalan dengan penelitian terdahulu yang dilakukan Mukti, Haryono dan Marlina (2017)

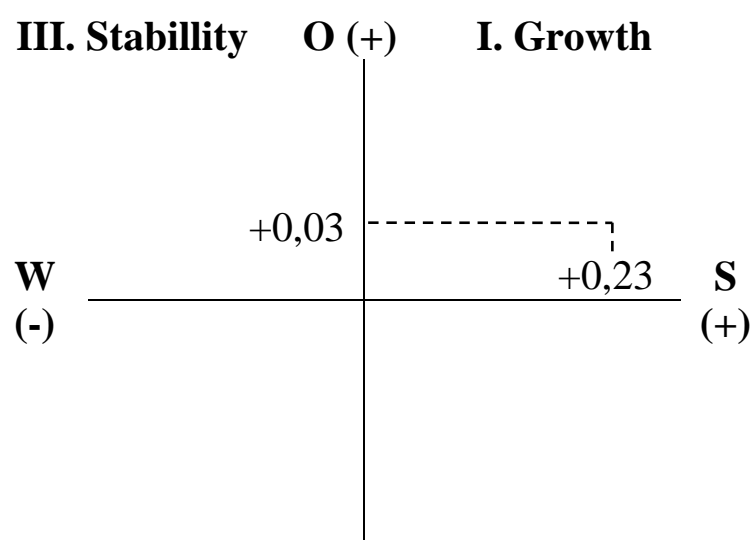

\section{Survival T (-) II. Diversifikasi}

Gambar 1. Diagram SWOT usaha jamur merang

tentang Analisis finansial dan strategi pengembangan usahatani jamur tiram putih di Desa Pampangan Kecamatan Sekincau Kabupaten Lampung Barat.

Penelitian ini tidak sejalan dengan penelitian terdahulu yang dilakukan Mukti, Haryono dan Marlina (2017) tentang Analisis finansial dan strategi pengembangan usahatani jamur tiram putih di Desa Pampangan Kecamatan Sekincau Kabupaten Lampung Barat. Pada penelitian terdahulu diketahui hasil diagram SWOT pada budidaya jamur tiram berada pada kuadaran 2, sedangkan pada penelitian ini budidaya jamur merang diketahui berada pada kuadran 1. Hal ini menunjukkan bahwa budidaya jamur merang berada pada posisi tumbuh.

\section{Strategi Prioritas Budidaya Jamur Merang}

Strategi prioritas analisis SWOT didapatkan dari penyilangan faktor internal dan eksternal yang terdiri dari $(\mathrm{S}><\mathrm{O}),(\mathrm{S}\rangle\langle\mathrm{T}),(\mathrm{W}\rangle\langle\mathrm{O})$ dan $(\mathrm{W}><\mathrm{T})$. Penyilangan tersebut menghasilkan 100 alternatif strategi yang kemudian dipilih 10 strategi prioritas yang paling sesuai dengan visi, misi dan objek budidaya jamur merang. 10 strategi prioritas budidaya jamur merang adalah :

1. Meningkatkan produksi jamur merang yang berkualitas agar dapat mengikuti perkembangan teknologi yang ada.

2. Mengantisipasi produksi yang tidak stabil dengan penerapan teknologi dalam usahatani jamur merang.

3. Melakukan promosi usaha jamur merang untuk memenuhi permintaan konsumen terhadap jamur merang.

4. Melakukan promosi usaha jamur merang untuk menghadapi munculnya pesaing sejenis. 
5. Meningkatkan hubungan dengan pelanggan untuk menghadapi munculnya pesaing sejenis.

6. Meningkatkan produksi jamur merang yang berkualitas guna mendapatkan bantuan fisik dan non fisik dari pemerintah.

7. Meningkatkan produksi jamur merang yang berkualitas dengan penerapaan teknologi dalam usahatani jamur merang.

8. Melakukan promosi usaha jamur merang untuk meningkatkan daya saing dengan pesaing sejenis.

9. Melakukan pembukuan dalam usaha jamur merang agar dapat mengikuti perkembangan teknologi yang ada.

10. Meningkatkan produksi jamur merang yang berkualitas dengan kondisi suhu kumbung yang terjaga untuk usaha jamur merang.

\section{KESIMPULAN}

Secara finansial budidaya jamur merang layak dan menguntungkan untuk diteruskan karena memiliki nilai NPV yang lebih dari 0 , Net B/C dan Gross B/C yang lebih dari 1, memiliki nilai Payback Period yang lebih pendek dari umur ekonomis dan nilai IRR yang lebih besar dari tingkat suku bunga. Strategi yang diperlukan untuk pengembangan budidaya jamur merang yaitu meningkatkan produksi jamur merang yang berkualitas, meningkatkan hubungan dengan pelanggan dan mulai melakukan promosi budidaya jamur merang guna memperluas jaringan pasar serta melakukan pembukuan dalam budidaya jamur merang.

\section{DAFTAR PUSTAKA}

Chandra R, Lestari DAH, Situmorang S. 2014. Analisis usahatani dan pemasaran jamur tiram dengan cara konvensional dan jaringan (multi level marketing) di provinsi lampung, Jurnal Ilmu Ilmu Agribisnis, 2(1): 38-47. httphttp://jurnal.fp.unila.ac.id/index.php/JIA/a rticle/view/559/521. [24 november 2019]

Dinas Pertanian Tanaman Pangan dan Hortikultura Provinsi Lampung. 2017. Basis Data Pertanian Provinsi Lampung. Dinas Pertanian Tanaman Pangan dan Hortikultura Provinsi Lampung. Bandar Lampung.
Devy J, Hasyim AI, Situmorang S. 2019. Analisis kelayakan finansial dan risiko usaha budidaya jamur tiram di provinsi lampung, Jurnal Ilmu Ilmu Agribisnis, 6(4): 347-354. http://jurnal.fp.unila.ac.id/index.php/JIA/articl e/view/3050/2427. [14 November 2019]

Karsiningsih E. 2016. Analisis kelayakan finansial dan strategi pengembangan teh gaharu di kabupaten bangka tengah (studi kasus: teh gaharu "aqilla" gapoktan alam jaya lestari), AGRARIS, $2(2)$ : 142-151. http://journal.umy.ac.id/index.php/ag/article/v iew/2280/2250. [14 November 2019]

Kementrian Pertanian. 2017. Basis Data Harga Komoditas Pertanian. http://www.pertanian. go.id/. [25 Oktober 2017]

Kurniawan A. 2011. Ketika dunia dijamuri pasar jamur.http://www.neraca.co.id/article/7327/ke tika-dunia-dijamuri-pasar-jamur. [25 Oktober 2017]

Mukti OP, Haryono D, Marlina L. 2017. Analisis finansial dan strategi pengembangan usahatani jamur tiram putih di desa pampangan kecamatan sekincau kabupaten lampung barat, Jurnal Ilmu Ilmu Agribisnis, 5(1): 31-39. http://jurnal.fp.unila.ac.id/index.php/JIA/articl e/view/1672/1498. [14 November 2019]

Munawar FR, Kartika JG. 2017. Produksi dan kualitas jamur merang (volvariella volvaceae) pada kelompok tani "mitra usaha" kabupaten karawang, Buletin Agrohorti, 5(2): 264-273. https://journal.ipb.ac.id/index.php/bulagron/ar ticle/view/16807/12243. [24 November 2019]

Novarinka, J. 2017. Ingin Usaha Jamur Merang, Harus Tahu Harga Jamur Merang Per Kilo. http://www.siapabisnis.com/2017/06/inginusaha-jamur-merang-harus-tahu.html Januari 2020]

Rangkuti F. 2006. Analisis SWOT Teknik Membedah Kasus Bisnis. Gramedia. Jakarta.

Wiratma AF, Wibowo Y, Purnomo BH. 2015. Studi analisis kelayakan finansial pembudidayaan jamur merang (volvariella volvaceae), Berkala Ilmiah Pertanian, 1(1): $\mathrm{xx}$-xx.

http://repository.unej.ac.id/handle/123456789/ 68921. [14 November 2019] 